This item was submitted to Loughborough's Research Repository by the author.

Items in Figshare are protected by copyright, with all rights reserved, unless otherwise indicated.

\title{
Parental strategies used in the family meal session of family-based treatment for adolescent anorexia nervosa: Links with treatment outcomes
}

PLEASE CITE THE PUBLISHED VERSION

http://dx.doi.org/10.1002/eat.22647

PUBLISHER

(c) Wiley

VERSION

AM (Accepted Manuscript)

\section{PUBLISHER STATEMENT}

This work is made available according to the conditions of the Creative Commons Attribution-NonCommercialNoDerivatives 4.0 International (CC BY-NC-ND 4.0) licence. Full details of this licence are available at: https://creativecommons.org/licenses/by-nc-nd/4.0/

\section{LICENCE}

CC BY-NC-ND 4.0

\section{REPOSITORY RECORD}

White, Hannah J., Emma Haycraft, Sloane Madden, Paul Rhodes, Jane Miskovic-Wheatley, Andrew Wallis, Michael Kohn, and Caroline Meyer. 2019. "Parental Strategies Used in the Family Meal Session of Familybased Treatment for Adolescent Anorexia Nervosa: Links with Treatment Outcomes". figshare. https://hdl.handle.net/2134/23062. 
Parental strategies used in the family meal session of Family-Based Treatment for adolescent anorexia nervosa: Links with treatment outcomes.

Dr Hannah J White ${ }^{1}$, Dr Emma Haycraft ${ }^{1 *}$, Dr Sloane Madden², Dr Paul Rhodes ${ }^{2}$, Dr Jane Miskovic-Wheatley ${ }^{2}$, Andrew Wallis ${ }^{2}$, Prof. Michael Kohn² \& Prof. Caroline Meyer ${ }^{3,4}$

1. Loughborough University Centre for Research into Eating Disorders, Loughborough University, Loughborough, UK.

2. Eating Disorder Service, The Children's Hospital, Westmead, Sydney, Australia.

3. WMG, University of Warwick, Coventry, UK

4. University Hospitals Coventry and Warwickshire NHS Trust, Coventry, UK

* Address correspondence to: Dr Emma Haycraft, Loughborough University Centre for Research into Eating Disorders, School of Sport, Exercise \& Health Sciences, Loughborough University, Loughborough, Leicestershire, LE11 3TU, UK. Email: E.Haycraft@lboro.ac.uk, Tel. +44(0)1509 228160.

Running head: MEALTIME STRATEGIES AND AN TREATMENT OUTCOMES...

Text word count: 1431

Abstract word count: 163 


\begin{abstract}
Objective: Examine relationships between parental mealtime strategies used in the family meal session of Family-Based Treatment (FBT) and adolescent outcomes at EOT (session 20).
\end{abstract}

Method: Eighteen families with an adolescent receiving FBT-AN participated.

Parental strategies during videoed family meals were assessed using a family mealtime coding system. Change scores were calculated for both adolescent \%EBW and EDE scores.

Results: Increased use of parental direct and non-direct eating prompts during the family meal was associated with greater adolescent weight gain at EOT. Use of parental mealtime strategies was not associated with any significant change in adolescent eating psychopathology at EOT.

Discussion: Parental verbal eating prompts during the family meal may be effective in promoting short-term weight gain. During the family meal session, parents should be encouraged to maintain a direct focus on their adolescent child's eating behaviour which may assist their child with food consumption and potential weight gain. Further research examining food-based interactions among parents and their adolescent child with $A N$ is needed.

Keywords: Adolescent anorexia nervosa; Family-based treatment; Parental feeding strategies; Treatment outcomes; Weight gain. 


\section{Parental strategies used in the family meal session of Family-Based Treatment for adolescent anorexia nervosa: Links with treatment outcomes}

The treatment of choice for adolescent anorexia nervosa (AN) is Family BasedTreatment (FBT). ${ }^{1,2}$ A primary focus in early sessions is behavioural change to achieve weight restoration. ${ }^{3}$ At this stage, as the eating disorder is conceptualised as controlling the adolescent, parents are assigned temporary control over their child's eating ${ }^{4,5}$ and given responsibility for ensuring weight gain. ${ }^{6}$ Weight gain by FBT session four is a significant predictor of higher weight at the end of treatment $(\mathrm{EOT})^{3,7,8}$ and remission at EOT and 12month follow-up. ${ }^{8}$ Thus, the first four sessions are critical for a positive outcome. The family meal (FM) occurs within this period and provides opportunity for parents to feel empowered via success in re-feeding their child..$^{4,5}$

Strategies that parents commonly utilise during the FM to encourage food consumption are documented. ${ }^{9}$ Behavioural prompts (direct and non-direct eating prompts and physical prompts) occur most frequently and are more successful in promoting food intake than strategies like offering food-related choices. ${ }^{9}$ However, while these strategies are considered 'helpful' within the FM, little is known about their relationship to longer-term outcomes.

Throughout FBT, greater parental control over AN behaviour has been shown to predict weight gain. ${ }^{10}$ However, within the FM, behaviours suggestive of parental control and pressure to eat, (such as presenting or serving food) occur more among the parents of adolescents who didn't respond early to treatment. ${ }^{11}$ Therefore, there remains confusion regarding the use of parental control and treatment outcomes.

In summary, parental behavioural food prompts used during the FM promote food consumption. ${ }^{9}$ However, parental control during the FM may be associated with less successful recovery in the longer term. ${ }^{11}$ Hence, the longer term outcomes of using parental 
strategies during the FM remain unclear. This study aimed to explore the relationships between the use of parental mealtime strategies during the FM and adolescent weight and eating psychopathology outcomes at EOT.

\section{Method}

Participants

Twenty-nine adolescents receiving FBT for AN and their families participated (as described elsewhere ${ }^{9}$ ). Participants were a subset recruited for a RCT (Madden et al. ${ }^{12}$ ). Where translators were present $(n=2)$, paradoxical interventions utilised $(n=6)$, or a full dataset unavailable $(n=3)$, participants were excluded. A final sample of 18 adolescents ( 1 male) and their families remained. At FBT session two, adolescents had a mean age of 15.1 years $(S D=1.56)$ and a mean percentage expected body weight (\%EBW) of $89.4 \%$ $(\mathrm{SD}=6.49)$. Most were White (83\%). Thirteen (72.2\%) were diagnosed AN-R and five AN-BP (27.8\%). Average illness duration was 9.83 months (SD: 8.95). Before commencing FBT, all had received inpatient treatment ${ }^{12}$ ( 7 for weight restoration, 11 for medical stabilization). Adolescents received a mean of 27 FBT sessions ( $S D=9.55 ; 15$ to 46 ) over an average of 29.77 weeks $(S D=7.89 ; 18$ to 45$)$.

Measures and procedure

\section{$\underline{\text { Adolescent measures }}$}

As part of the RCT, ${ }^{12}$ participants completed the Eating Disorder Examination (EDE), ${ }^{13-15}$ and were regularly weighed and measured. Height and weight at session two and EOT (or session 20, whichever came first) were utilised and \%EBW was calculated. EDE at admission and EOT (or session 20) were utilised.

\section{Family meal observations}


Average meal duration during session two was 33 minutes ( $S D=18$; range 7 to 68 ). Parents are tasked with encouraging their child to eat one more mouthful than he/she is prepared to. ${ }^{4,5}$ Thirteen families (72.2\%) attempted to encourage their child to eat an additional mouthful, with 12 families (66.7\%) succeeding.

Family Mealtime Coding System - Adolescents (FMCS-A) ${ }^{9}$

The study used an adapted version of the Family Mealtime Coding System $\left(\mathrm{FMCS}^{16}\right)$, the FMCS-A, developed previously to examine interactions between parents and adolescents with AN which occur while food is present. ${ }^{9}$ The five strategies occurring most frequently during the $\mathrm{FM}^{9}$ were included in this study.

Direct eating prompts: Parental vocalisations which directly prompt/pressure the adolescent to eat.

Non-direct eating prompts: Parental vocalisations which encourage/suggest eating.

Physical prompts: Parental physical movement to prompt/encourage eating/drinking.

Autonomous comments: Parents offering the adolescent food-related choices.

Information provision: Parents providing informative comments about eating.

A second, independent rater coded $39 \%(n=7)$ of videos. Inter-rater reliability was very good in all but two instances $\left(r>.781, p<.01\right.$; see White et al. $\left.{ }^{9}\right)$.

Data analysis

Composite scores were calculated for each FMCS-A subscale (by summing mothers' and fathers' scores), as has been reported previously in FBT research. ${ }^{11}$ Outcome change 
scores were calculated. As described elsewhere, ${ }^{17}$ baseline (or session two) scores were subtracted from EOT scores for both EDE global and \%EBW.

While families typically received 20 FBT sessions, ${ }^{4,5}$ some received less if they achieved earlier recovery ${ }^{12}$. As a result, the number of FBT sessions families received was adjusted for.

Most variables were not normally distributed (Shapiro Wilk tests). However, partial correlations were used as there is no non-parametric equivalent. Two-tailed partial correlations (adjusting for $n$ FBT sessions) examined associations between the parental strategies and outcomes (\%EBW and EDE global change scores). P $\leq .05$ was adopted throughout.

\section{Results}

\section{Descriptive statistics}

Mean \%EBW at EOT was above 95\%; a cut-off value used to denote remission ${ }^{3,12,18}$ (Table 1). In addition, at session two, $11 \%$ of adolescents had a \%EBW above $95 \%$, and $50 \%$ of adolescents at EOT.

\section{TABLE 1}

EDE scores were similar to adult community norms within 1 standard deviation, with slightly higher scores at EOT.

Parental mealtime strategies at session two and adolescent outcomes

TABLE 2 
Mealtime strategies and AN treatment outcomes...

Parental direct and non-direct eating prompts were significantly associated with \%EBW change scores from the FM to EOT (Table 2), indicating that use of parental direct and non-direct eating prompts during the FM was associated with greater weight gain at EOT. There were no significant associations between any parental mealtime strategy and changes in adolescent EDE global scores from baseline to EOT.

\section{Discussion}

This study examined relationships between strategies parents use with their adolescent child with AN during the FM of FBT and treatment outcomes (weight and eating psychopathology). In relation to weight outcomes, higher use of direct and non-direct eating prompts during the FM was linked with greater weight gain at EOT. Direct and non-direct eating prompts have previously been associated with promoting food intake during the FBT $\mathrm{FM}^{9}{ }^{9}$ The current study findings suggest that parental use of verbal food-related prompts during the FM might promote weight gain during treatment. A direct focus on eating by parents may make the make the process of eating psychologically easier for the adolescent as they are responding to instruction, rather than choosing to eat. Previously, greater parental control over AN behaviour has been shown to predict weight gain. ${ }^{10}$

In relation to eating psychopathology, no significant associations were found between any parental mealtime strategies used during the FM and changes in eating psychopathology at EOT. This finding may seem unsurprising given that parental strategies are utilised during the FM to promote adolescent food consumption and subsequently weight gain, not to improve eating psychopathology. However, an additional reason for this finding, as previously discussed elsewhere ${ }^{19}$ is that EDE scores are resistant to change. ${ }^{20}$ Subsequently, these scores may not be the best indicator of outcome within this timeframe and longer term changes should be considered. 
This is the first study to examine relationships between observed strategies that parents use during the FM and outcomes. However, it is important to acknowledge the limitations and difficulties of analysing such a complex session. As often seen with clinical research, the current sample size is small and all participants were recruited from the same clinic, consequently all findings should be interpreted with caution. It should also be noted that the FM provides a snapshot of the interactions parents have with their children. For some families, few parental strategies might be observed during this specific occasion, due to adolescents eating uncharacteristically well, or due to parental avoidance of challenging the $\mathrm{AN} .{ }^{21}$ Some families may find their own strategies to promote food intake/weight gain outside the FM, perhaps later during treatment. In addition to this, there are also home environment factors which could confound the results (e.g., use of more distractions, such as TV). Exploring the strategies parents use at home with their child with $\mathrm{AN}$, and how they compare to those used in the FM would be advantageous. Furthermore, within the current study, the category direct eating prompts focuses on the content of the interaction not the emotional tone, an aspect which is linked to weight outcomes within FBT. ${ }^{11}$ Future research should examine relationships between the emotional tone surrounding parental strategies and outcomes.

For professionals working with individuals with AN, the encouraged use of parental verbal eating prompts during the FM may be effective short-term strategies for physical recovery, i.e., in helping the adolescent to gain weight. Further research examining how parents of adolescents with AN interact around food and the longer term outcomes of such interactions is warranted. 
Mealtime strategies and AN treatment outcomes...

\section{References}

1. American Psychiatric Association. Practice Guidelines for the Treatment of Patients with Eating Disorders ( $3^{\text {rd }}$ ed.); 2010. Available online at:

http://psychiatryonline.org/pb/assets/raw/sitewide/practice guidelines/guidelines/eatingdisor ders.pdf. Accessed 30th March 2015.

2. Loeb KL, Le Grange D. Family-based treatment for adolescent eating disorders: Current status, new applications and future directions. Int J Child Adolesc Health 2009;1:243-254.

3. Lock J, Couturier J, Bryson S, Agras WS. Predictors of dropout and remission in family therapy for adolescent anorexia nervosa in a randomized clinical trial. Int J Eat Disord 2006;39:639-647.

4. Lock J, Le Grange D, Agras WS, Dare C. Treatment manual for anorexia nervosa: A family-based approach. New York: The Guildford Press; 2001.

5. Lock J, Le Grange D. Treatment manual for anorexia nervosa: A family-based approach ( $2^{\text {nd }}$ ed. $)$. New York: Guildford Press; 2012.

6. Murray SB, Wallis A, Rhodes P. The questioning process in maudsley family-based treatment. Part 1: Deviation amplification. Contemp Fam Ther 2012;34:582-592.

7. Doyle PM, Le Grange D, Loeb K, Celio Doyle A, Crosby RD. Early response to familybased treatment for adolescent anorexia nervosa. Int J Eat Disord 2010;43:659-662.

8. Madden S, Miskovic-Wheatley J, Wallis A, Kohn M, Hay P, Touyz S. Early weight gain in family-based treatment predicts greater weight gain and remission at the end of treatment and remission at 12 month follow-up for adolescent anorexia nervosa. Int J Eat Disord 2015a;48:919-922.

9. White HJ, Haycraft E, Madden S, Rhodes P, Miskovic-Wheatley J, Wallis A, et al. How do parents of adolescent patients with anorexia nervosa interact with their child at mealtimes? A study of parental strategies used in the family meal session of family-based treatment. Int $\mathrm{J}$ Eat Disord 2015;48:72-80. 
10. Ellison R, Rhodes P, Madden S, Miskovic J, Wallis A, Baillie A, et al. Do the components for manualized family-based treatment for anorexia nervosa predict weight gain? Int $\mathrm{J}$ Eat Disord 2012;45(4):609-614.

11. Darcy AM, Bryson SW, Agras S, Fitzpatrick KK, Le Grange D, Lock J. Do in-vivo behaviors predict early response in family-based treatment for anorexia nervosa? Behav Res Ther. 2013;51(11):762-766.

12. Madden S, Miskovic-Wheatley J, Wallis A, Kohn M, Lock J, Le Grange D, et al. A randomized controlled trial of in-patient treatment for anorexia nervosa in medically unstable adolescents. Psych Med 2015b;45:415-427.

13. Cooper Z, Fairburn CG. The eating disorder examination: A semi-structured interview for the assessment of the specific psychopathology of eating disorders. Int $\mathrm{J}$ Eat Disord $1987 ; 6: 1-8$

14. Fairburn CG, Beglin SJ. The assessment of eating disorders: Interview or self-report questionnaire? Int J Eat Disord 1994;16: 363-370.

15. Bryant-Waugh RJ, Cooper PJ, Taylor CL, Lask BD. The use of the eating disorder examination with children: a pilot study. Int J Eat Disord 1996;19:391-397.

16. Haycraft E, Blissett J. Maternal and paternal controlling feeding practices: Reliability and relationships with BMI. Obesity 2008;16(7):1552-1558.

17. Gilbert N, Meyer C. Fear of negative evaluation and the development of eating psychopathology: A longitudinal study among nonclinical women. Int J Eat Disord $2005 ; 37: 307-312$

18. Lock J, Le Grange D, Agras WS, Moye A, Bryson SW, Jo B. Randomized clinical trial comparing family-based treatment to adolescent focused individual therapy for adolescents with anorexia nervosa. Arch Gen Psychiatry 2010;67:1025-1032.

19. Lock J, Le Grange D, Agras WS, Fitzpatrick KK, Jo B, Accurso E, et al. Can adaptive treatment improve outcomes in family-based therapy for adolescents with anorexia nervosa? 
Feasibility and treatment effects of a multi-site treatment study. Behav Res Ther 2015;73:9095.

20. Couturier J, Lock J. What is remission in adolescent anorexia nervosa? A review of various conceptualizations and quantitative analysis. Int J Eat Disord 2006;39:175-183. 21. Godfrey K, Rhodes P, Miskovic-Wheatley J, Wallis A, Clarke S, Kohn M, et al. Just one more bite: A qualitative analysis of the family meal in family-based treatment for anorexia nervosa. Eur Eat Disord Rev 2015;23:77-85. 
Table 1: Mean values, standard deviations and range scores for parental mealtime strategies and adolescent outcomes at end of treatment $(\mathrm{N}=18)$.

Mean (SD) Range

\section{Parental mealtime strategies $^{1}$}

Total direct eating prompts

$22.4(36.7)$

$0-131$

Total non-direct eating prompts

$$
0-14
$$

Total physical prompts

Total autonomous comments

$0-43$

Total information provision

$$
0-12
$$

\section{Adolescent outcomes at EOT}

Percentage expected body weight (\%EBW)

$96.4(5.73)$

$88.3-109$

Change in \%EBW from session two to EOT

EDE global score

Change in EDE global from baseline to EOT

EOT $=$ End of treatment / session 20 (whichever came first)

\footnotetext{
${ }^{1}$ Both parents were present at the session for the majority of families $(n=13)$. Of the remaining families where only one parent attended the session $(n=5)$, two of these families had an additional adult from the family present (a grandmother), however, comments from additional adults were not included in any analyses.
} 
Table 2: Partial correlations (adjusting for number of FBT sessions) between parental mealtime strategies and the change in both percentage expected body weight (\%EBW) and Eating Disordered Examination (EDE) global scores for the adolescent between baseline or session two, and end of treatment $(\mathrm{N}=18)$.

\section{Adolescent Treatment Outcomes}

Change in adolescent

\%EBW from session two to
Change in adolescent EDE from baseline to EOT

\section{EOT}

\begin{tabular}{lll}
\hline Parental Mealtime Strategy & \\
Direct eating prompts & $0.58^{*}$ & 0.15 \\
Non-direct eating prompts & $0.53^{*}$ & -0.20 \\
Physical prompts & 0.43 & 0.23 \\
Autonomous comments & 0.25 & 0.21 \\
Information provision & 0.48 & -0.03 \\
\hline EOT = End of treatment / session 20 (whichever came first) & \\
${ }^{*} \mathrm{p} \leq 0.05$ & &
\end{tabular}


Acknowledgements: The authors thank Charlotte Miles for her assistance with the secondary coding of the videos.

Funding: Supported by grant 457235 from the National Health and Medical Research Council of Australia (NHMRC) with the following Australian Clinical Trials Register number: ACTRN012607000009415.

Conflict of interest: The authors have no conflict of interest to declare. 